\title{
Implications of public policy on breast reconstruction: a survey of New York State breast surgeons on the breast cancer provider discussion law
}

\author{
Yoshiko Toyoda ${ }^{1,2}$, Alexandra J. Lin ${ }^{1}$, Christine H. Rohde ${ }^{1}$ \\ ${ }^{1}$ Division of Plastic and Reconstructive Surgery, NewYork-Presbyterian Hospital, New York, NY, USA; ${ }^{2}$ Division of Plastic and Reconstructive \\ Surgery, Hospital of the University of Pennsylvania, Philadelphia, PA, USA \\ Contributions: (I) Conception and design: Y Toyoda, CH Rohde; (II) Administrative support: CH Rohde; (III) Provision of study materials or patients: \\ CH Rohde; (IV) Collection and assembly of data: Y Toyoda; (V) Data analysis and interpretation: All authors; (VI) Manuscript writing: All authors; \\ (VII) Final approval of manuscript: All authors. \\ Correspondence to: Christine H. Rohde, MD, MPH. NewYork-Presbyterian/Columbia Herbert Irving Pavilion, 161 Fort Washington Avenue 5-506, \\ New York, NY 10032, USA. Email: Chr2111@cumc.columbia.edu.
}

Background: Breast reconstruction is covered by insurance, but reconstruction rates remain low. The New York State (NYS) Breast Cancer Provider Discussion Law of 2010 mandated breast surgeons provide education and plastic surgical referral at the time of cancer diagnosis. We previously demonstrated increased reconstruction rates from 2008 to 2014, especially among historically disadvantaged patients. To supplement these results, we surveyed NYS breast surgeons on law awareness and changes in their practices.

Methods: An anonymous electronic survey was distributed to NYS American College of Surgeons members practicing breast surgery. Participants were queried on demographics; law awareness; discussion of reconstruction, referral, and follow up before the law and currently; and impact of the law on their practices, specifically with regard to social disparities.

Results: Of the 281 functioning contacts, 32 (11.4\%) responded, of which 28 performed breast surgery. Half of the included respondents were female, $35.7 \%$ in academic practice, and $85.7 \%$ aware of the law, most commonly through surgical societies (25.0\%). Prior to the law, $89.3 \%$ always discussed reconstruction, which increased to $96.4 \%$ currently. Only $14.3 \%$ responded that more than $75 \%$ of patients sought reconstruction prior to the law, which increased to $21.4 \%$. Rates of always following up increased from $78.6 \%$ to $82.1 \%$. While most respondents did not see changes in their own patient demographic, they agreed the law would theoretically benefit underrepresented minorities.

Conclusions: This is the first provider-based study on this NYS law. Continued outcomes- and providerbased research may inform future health policies to improve quality of life of breast cancer patients.

Keywords: Breast reconstruction; breast cancer; provider survey; patient education; New York State (NYS)

Received: 16 January 2020; Accepted: 17 July 2020; Published: 25 September 2020.

doi: 10.21037/jhmhp-20-13

View this article at: http://dx.doi.org/10.21037/jhmhp-20-13

\section{Introduction}

Nearly 1 in 8 women in the U.S. develop breast cancer (1). Mastectomy, including prophylactic mastectomy, is an everimportant treatment option, but leaves women disfigured. Breast reconstruction is an accepted component of the complete multidisciplinary care of the breast cancer patient due to its substantial psychological benefit and contribution to improved quality of life (2-5). Its significance is reflected in the Women's Health and Cancer Rights Act (1998) which mandated that breast reconstruction be covered under insurance. Despite incremental increases, subsequent studies revealed that reconstruction rates have remained low 
with a national estimate of $42 \%$ (6).

Two main identified barriers to reconstructive care were patients' lack of understanding of reconstructive options and inconsistent referral patterns by the breast surgeon (7-9). These studies found that breast surgeons act as gatekeepers to reconstructive care. Largely in response to these studies, New York State (NYS) instituted the Breast Cancer Provider Discussion Law of 2010, which was enacted in 2011 and required patient education and expedient referral to plastic surgeons at the time of breast cancer diagnosis. Previous research from our group has demonstrated that from 2008 to 2014, breast reconstruction rates increased, especially among patients from historically disadvantaged ethnicities, those of lower socioeconomic status, and patients older than 55 (10). While we hypothesize that the NYS law contributed to the overall increased rate and reduction in social disparities to reconstructive care, demonstrating causal effect solely from outcomes-based studies is difficult. An additional provider-based study, especially given that this law was an initiative to encourage physician-driven education, may corroborate with our previous study to better correlate the 2010 law with the outcomes. Herein, we present a survey of NYS breast surgeons on their awareness of the law and its impact on their practices with a particular emphasis on their impressions of changes in social disparities in breast reconstruction.

\section{Methods}

\section{Survey participants}

An anonymous electronic survey was distributed to members of the American College of Surgeons who were designated as practicing breast surgery in NYS using Google Forms (Google, LLC., Mountain View, CA). The Columbia University Medical Center Institutional Review Board determined that the survey met exemption criteria. The survey was emailed in three deployments between 10/16/18 and $1 / 28 / 19$. The participants were not provided any financial incentive to submit responses. Deidentified survey responses were recorded in a password-protected database.

\section{Survey questions}

Survey participants were queried on demographic information including: age range, gender, racial/ethnic background, geographical location, type of practice, whether they performed oncologic breast surgery, and when they began their practice in NYS. They then answered regarding their awareness of the Breast Cancer Provider Discussion Law of 2010, including how they learned of the law and whether it affected their referral patterns for breast reconstruction. Only participants who performed oncologic breast surgery were included in the analyses.

Next, the participants were asked the following questions regarding their practice patterns both prior to law enactment in 2011 and currently: routine discussion of reconstruction with patients undergoing breast surgery; referral of oncologic breast surgery patients to plastic and reconstructive surgeons; follow up with patients regarding breast reconstruction; and what proportion of their oncologic breast surgery patients received reconstruction. Regarding their current practice, the participants were additionally asked if their patients after law enactment in 2011 were aware of insurance coverage for reconstruction prior to discussion in the office.

Finally, participants were given the option to provide open-ended responses on how they thought the law impacted their practice; whether and how the law impacted the demographics of patients undergoing breast reconstruction; and how they thought breast reconstruction impacts patients who undergo oncologic breast surgery.

\section{Analyses}

All categorical variables were described by counts and percentages. The answer options comparing before and after law enactment were assigned numerical values: always/more than $75 \%$ (4), usually/50-75\% (3), sometimes/25-50\% (2), and never/less than 25\% (1). Differences between these two groups were tested by paired, two-tailed $t$-test. Tests of significance were performed on all outcomes using an alpha value of 0.05 . Statistical analysis was conducted with Prism 7.0 (GraphPad Software, San Diego, CA).

\section{Results}

\section{Demographic data}

Of the 288 breast surgeons who were identified in the American College of Surgeons directory, 282 provided email contact information. Of these, the email was undeliverable to 1 email address and 1 participant responded that he/she had been retired since prior to law enactment. There were 32 total respondents, giving a response rate of $11.4 \%$. Of these, $28(87.5 \%)$ affirmed that they perform oncologic 
Table 1 Demographics ( $\mathrm{N}=28)$

\begin{tabular}{|c|c|c|}
\hline Variable & Subcategory & Value, n (\%) \\
\hline \multirow[t]{2}{*}{ Sex } & Female & $14(50.0)$ \\
\hline & Male & $14(50.0)$ \\
\hline \multirow[t]{7}{*}{ Age range } & $<30$ & $0(0)$ \\
\hline & $30-39$ & $4(14.3)$ \\
\hline & $40-49$ & $5(17.9)$ \\
\hline & $50-59$ & $8(28.6)$ \\
\hline & $60-69$ & $8(28.6)$ \\
\hline & $70-80$ & $3(10.7)$ \\
\hline & $>80$ & $0(0)$ \\
\hline \multirow[t]{4}{*}{ Race/ethnicity } & White/Caucasian & $21(75.0)$ \\
\hline & Asian & $4(14.3)$ \\
\hline & Hispanic & $2(7.1)$ \\
\hline & Black/African & $1(3.6)$ \\
\hline \multirow[t]{5}{*}{ Type of practice } & Academic practice & $10(35.7)$ \\
\hline & $\begin{array}{l}\text { Multidisciplinary } \\
\text { specialty group }\end{array}$ & $7(25.0)$ \\
\hline & Private practice & 5 (17.9) \\
\hline & $\begin{array}{l}\text { Hospital employed } \\
\text { practice }\end{array}$ & $5(17.9)$ \\
\hline & Hybrid model & $1(3.6)$ \\
\hline \multirow[t]{3}{*}{ Practice setting } & Urban & $18(64.3)$ \\
\hline & Suburban & $7(25.0)$ \\
\hline & Rural & $3(10.7)$ \\
\hline
\end{tabular}

breast surgery, and only these respondents were included for further analyses. Fourteen respondents were male and 14 were female. Respondents had been practicing in NYS ranging from 1 to 43 years. Sixty-four point three percent, $25.0 \%$, and $10.7 \%$ practice in urban, suburban, and rural geographical settings, respectively. Practice settings varied, with $35.7 \%$ in academic practice, $25.0 \%$ in multidisciplinary specialty groups, $17.9 \%$ in private practice, $17.9 \%$ in hospital employed practice, and 3.6\% in hybrid models (Table 1).

\section{Awareness of the Breast Cancer Provider Discussion Law}

Of the respondents, $85.7 \%$ were aware of the Breast Cancer Provider Discussion Law of 2010. The most common route through which they learned about the law was through surgical societies at $25.0 \%$. The next most common were through the news media, their hospital/medical centers, or colleagues at $17.9 \%$ (Figure 1).

\section{Patient education and referral}

Prior to 2011, 89.3\% of respondents always discussed breast reconstruction with patients undergoing oncologic breast surgery which increased to $96.4 \%$ currently $(\mathrm{P}=0.2117)$ (Figure 2A). Prior to 2011, 67.9\% always, $21.4 \%$ usually, and $10.7 \%$ sometimes referred the patients to plastic and reconstructive surgeons. Currently, $71.4 \%$ always and $28.6 \%$ usually refer patients $(\mathrm{P}=0.1610)$ (Figure $2 B$ ). Currently, $46.4 \%$ of respondents found that patients are always, $10.7 \%$ usually, and $42.9 \%$ sometimes aware of insurance coverage for breast reconstruction prior to discussion (Figure 2C).

Prior to 2011, $14.3 \%$ of the respondents found that more than $75 \%$ of their patients who underwent oncologic breast surgery received breast reconstruction while $42.9 \%$ answered that $50-75 \%, 21.4 \%$ answered $25-50 \%$, and $21.4 \%$ answered less than $25 \%$ of their patients received reconstruction. This changed to $21.4 \%$ responding that more than $75 \%, 39.3 \%$ with $50-75 \%, 25.0 \%$ with $25-50 \%$, and $14.3 \%$ with less than $25 \%$ of their patients receive breast reconstruction currently ( $\mathrm{P}=0.0572)$ (Figure $2 D)$.

Of the respondents, $78.6 \%$ always, $17.6 \%$ usually, and $3.6 \%$ sometimes followed up with their patients regarding breast reconstruction prior to 2011 while $82.1 \%$ always and $17.9 \%$ usually follow up currently $(\mathrm{P}=0.4242$ ) (Figure $2 E$ ).

\section{Impact on practice}

Respondents overwhelmingly believed that breast reconstruction positively impacts women who undergo oncologic breast surgery, with $84.6 \%$ of those who completed the optional open-ended response volunteering this sentiment. They agreed that reconstruction often "provides an improved sense of self and wholeness after breast cancer" and "improves their [...] emotional state". One female respondent in a multidisciplinary specialty group elaborated: "interpersonal relationships, sexuality, and intimacy is more likely to be preserved. [...] The knowledge that asymmetries [...] can be addressed and corrected [...] gives women much more hope and much more optimism as they face the challenge of breast cancer treatment and survivorship." 


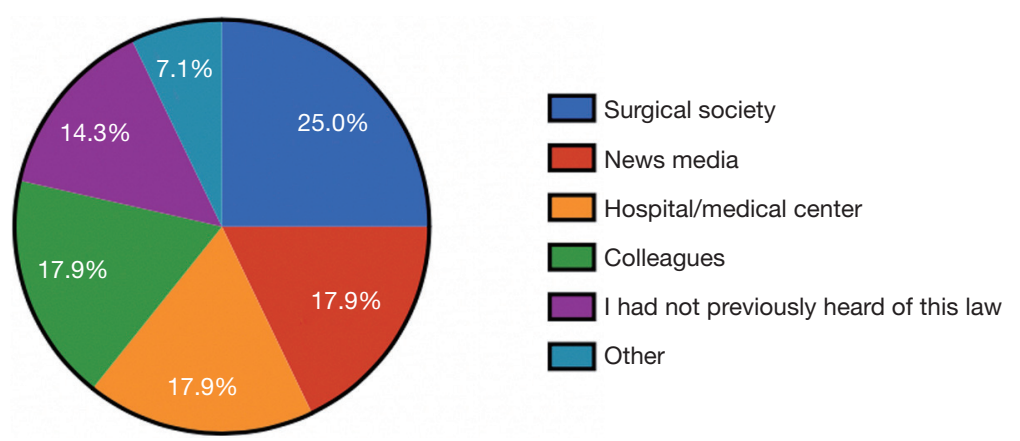

Figure 1 Source through which respondents learned of the Breast Cancer Provider Discussion law of 2010 (N=28).

A

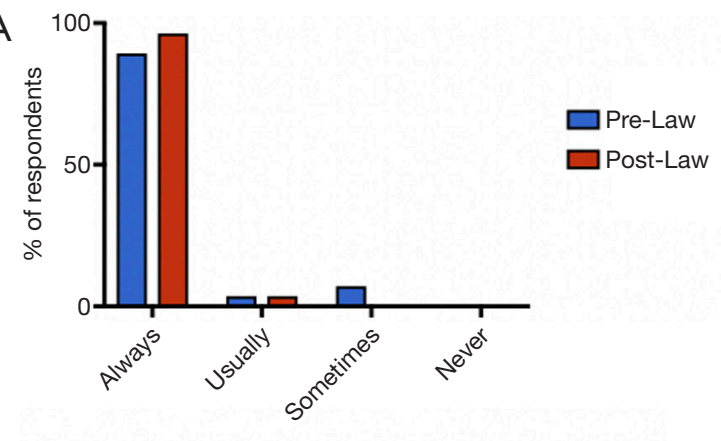

C

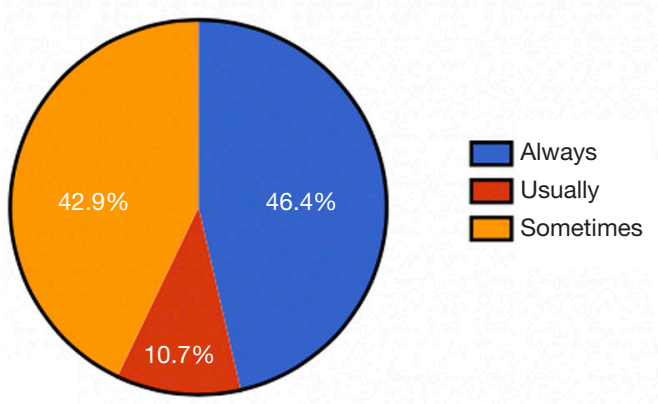

$\mathrm{E}$

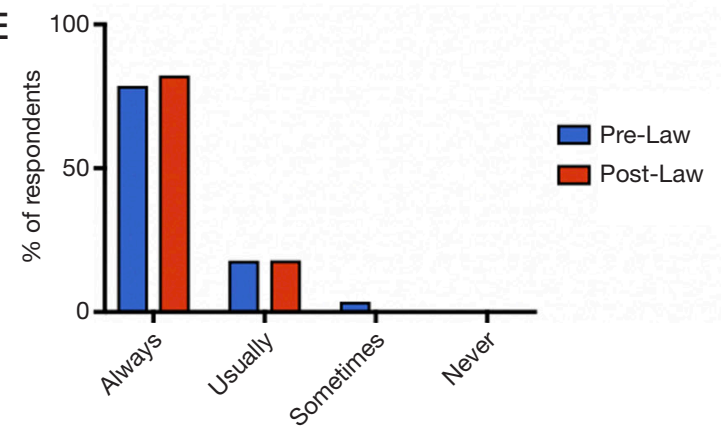

B

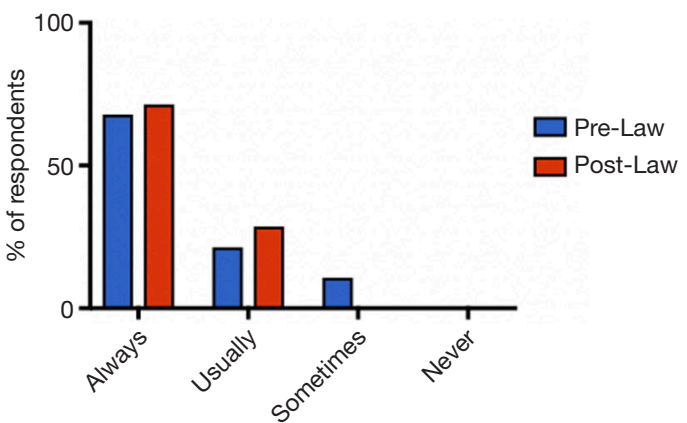

D

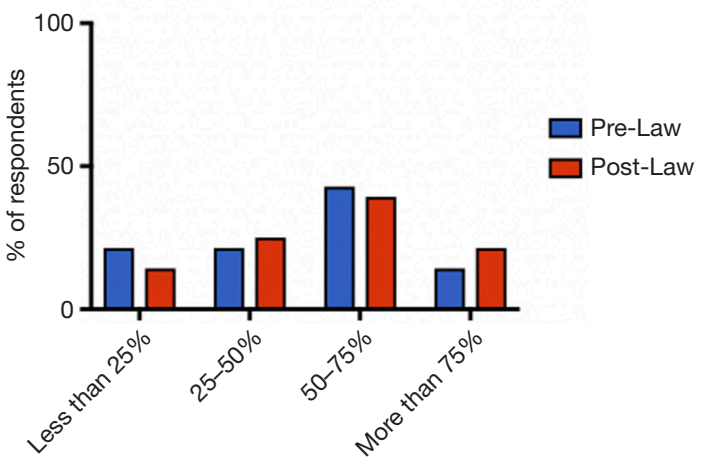

Figure 2 New York State breast surgeon practice (N=28). (A) Frequency of discussion of breast reconstruction prior to (blue) and after (red) law enactment ( $\mathrm{P}=0.2117)$. (B) Frequency of referral to reconstructive surgeon prior to (blue) and after (red) law enactment $(\mathrm{P}=0.1610)$. (C) Current patient awareness of insurance coverage for breast reconstruction. (D) Frequency of breast reconstruction prior to (blue) and after (red) law enactment $(\mathrm{P}=0.0572)$. (E) Frequency of follow up on reconstruction prior to (blue) and after (red) law enactment $(\mathrm{P}=0.4242)$. 
Table 2 Impact on practice

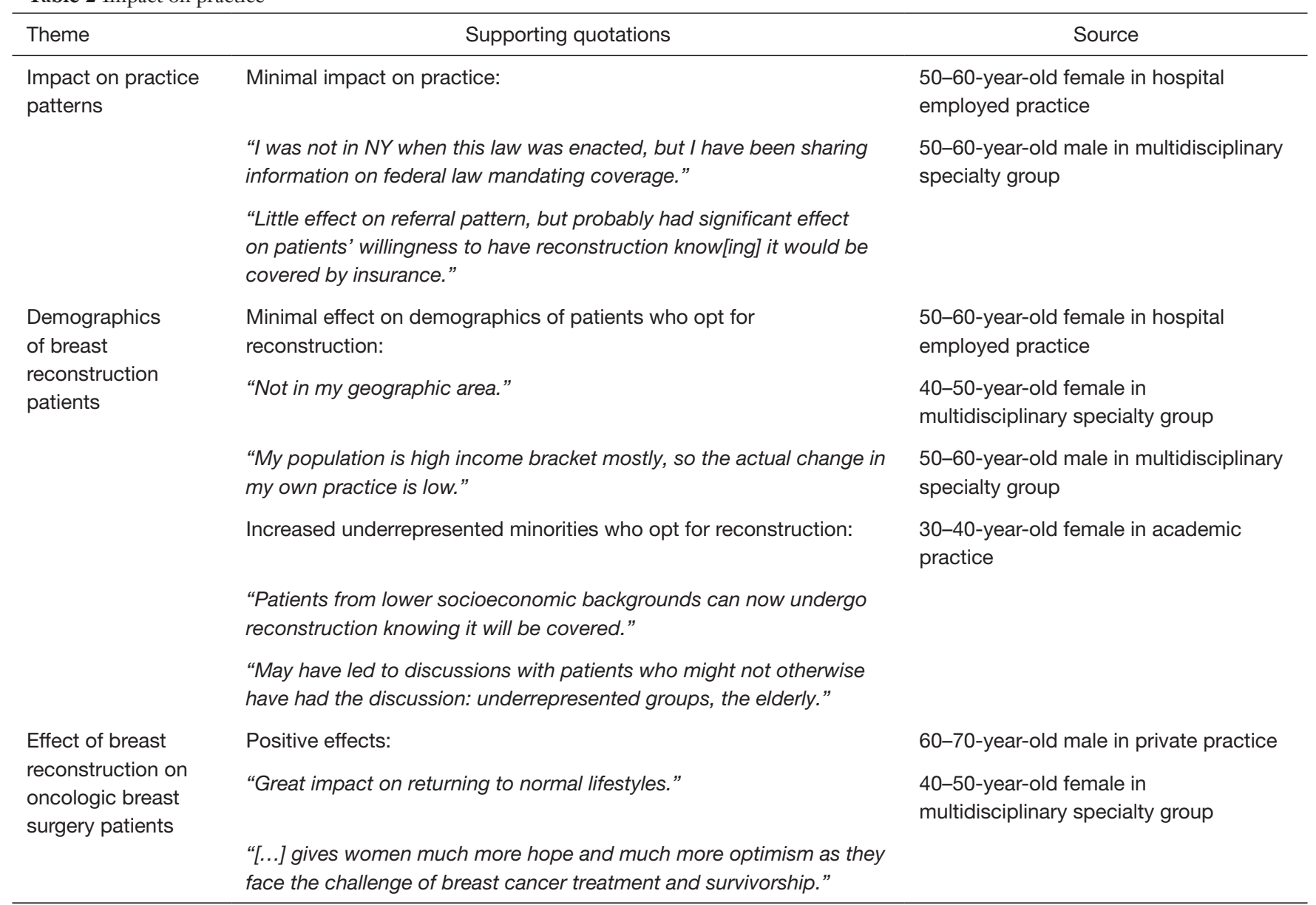

The impact of the law on the breast surgeons' practices ranged from none, improvement in patient care, and increase in plastic surgical referrals. One respondent noted that while it had not greatly impacted his/her own practice, knowledge of the law "has given me a solid platform with which to [...] put into place practice standards for my whole group to follow in offering reconstruction to the appropriate patients." While most respondents did not note a difference in the demographics of their own patients who opted for breast reconstruction, many agreed that the law would theoretically increase the number of underrepresented minorities who seek breast reconstruction, including "patients from lower socioeconomic backgrounds" and "underrepresented groups, the elderly" (Table 2).

\section{Discussion}

Cancer care is a multidisciplinary field in which plastic and reconstructive surgeons play a vital role in the recovery of the breast cancer patient. With improving survival after mastectomy and increased awareness of prophylactic options especially for those with genetic predispositions, breast reconstruction is an increasingly significant component of the complete care of the breast cancer patient. Breast cancer care encompasses numerous health professionals, including primary care providers, oncologists, psychiatrists, and social workers, as well as oncologic and reconstructive surgeons who were the foci of this present study (11). For optimal patient care, all of these elements ought to work in tandem with smooth communication. Poor coordination among these caregivers is a barrier to survivorship care and contributes to avoidable patient morbidity and mortality, fragmented care, inappropriate care, and increased costs (11). In turn, effective patient-provider relationships have been associated with improved treatment adherence, survival, and quality of life among cancer patients (12). It is therefore 
encouraging that $71 \%$ of our respondents always refer their mastectomy patients for breast reconstruction.

Patient health education by the provider is integral in comprehensive care. Unfortunately, health education and information dissemination are imperfect and not all patients will be aware of the treatment and reconstructive options available to them as indicated in numerous studies including the present study $(12,13)$. In particular, patient education is a particular barrier for racial and ethnic minority patients. Studies have demonstrated that patients of ethnic minority are at higher risk than White patients for poor communication and strained patient-provider relationships which may lead to delayed or nonstandard care (12). Various factors have been identified, including the minority patients' own beliefs, socioeconomic factors leading to reduced access, and cultural or community values (12). However, of all identifiable barriers, providers' recommendations were the most important influence on treatment decision-making (12). Provider communication and information giving were particularly important. Utilizing the California Health Interview Survey, May et al. found that nearly $20 \%$ of eligible men who did not receive colorectal cancer screening reported lack of provider recommendation as the main reason and that this was significantly greater among AfricanAmericans and Asians than in White men (14). Racial and ethnic differences in patient knowledge were significantly reduced after adjusting for provider communication style in a cross-sectional study of White, African American, and Latina breast cancer patients (15). These factors may contribute to the significantly worse mortality and delayed cancer detection rates in ethnic minorities and those of lower socioeconomic status. For example, when comparing mammogram prevalence, $72.1 \%$ of non-Hispanic White women over 40 had screening while only $39.5 \%$ of those who lacked health insurance coverage had this preventive measure, of which a large proportion were ethnic minorities $(16,17)$. A large portion of our respondents were also aware of the effect of socioeconomic disparities on access to breast reconstruction. Some cited their "geographic area" or "high income bracket" patient population as a reason for minimal change in the demographics of reconstruction patients, implying their awareness that zip code and income are significant determinants of access to reconstructive care.

Social disparities exist among breast reconstruction patients as well. A recent NSQIP study found that those of non-Caucasian race and older age (45 years or older) were negatively correlated with receiving immediate breast reconstruction (18). Butler et al. conjectured based on previous studies that these disparities were due to multiple factors including those which may be remedied by the provider, such as physician referral patterns or bias, access to a reconstructive surgeon, and patients' acumen regarding reconstruction options (18). In a qualitative survey study on perceptions regarding breast reconstruction among Asian immigrant women, source of information was integral to the women's pursuit of reconstruction (19). These participants were more likely to pursue reconstruction when the options were discussed by their breast surgeons rather than from other informative and/or misinformative sources such as community or family members, the media, or the internet (19). Thus, the importance of proactive discussion by the provider is particularly important for eligible patients whose culture or community is not already accepting of pursuing reconstruction. Interestingly, the majority of our respondents who found that the proportion of their patients who seek reconstruction increased were of racial/ethnic minorities themselves (Hispanic, Asian, Black/ African). While their responses are only their impressions, it is encouraging that providers of minority backgrounds find their reconstructive patient populations to be growing. This finding may translate to an upward trend in minority patients opting for reconstruction, especially as studies have shown patients prefer physicians of similar cultural or language backgrounds (19).

One seventh of our participants had not previously heard of the Provider Discussion Law before participating in the survey. While their lack of awareness of the law did not seem to impact all $14.3 \%$ of these respondents as many of them still referred their patients for reconstruction, improvement in dissemination of information regarding this policy as well as other health policies would be beneficial. Over $60 \%$ responded that they learned of the law through common academic venues, such as surgical societies, hospitals/medical centers, or colleagues. Further emphasis on progress by advocacy groups such as Plasty $\mathrm{PAC}$ at regional and national conferences may improve awareness. Additionally, more frequent communication between plastic surgeons and other healthcare professionals including breast surgeons, oncologists, and even primary care providers may enhance dissemination of information to patients. Suggestion of reconstruction or information regarding the insurance coverage status of reconstruction can be provided to the patients at numerous points in their breast cancer journey, from regular check-ups, diagnosis, and resection. The entire healthcare team may collaborate to ensure that patients receive pertinent materials to make 
the most informed decisions.

Nearly $18 \%$ of breast surgeons learned about the Provider Discussion Law through the news media. The media may be an effective means of enhancing visibility of reconstructive options both to healthcare providers as well as to patients. Analysis of media effects for cancer screening demonstrated short-duration television campaigns combined with easy access to services, and reminder letters were associated with population-wide increases (20). Videos on social media platforms were also demonstrated to be effective messaging strategy to raise awareness of health risk factors such as tobacco on breast cancer among youth (21). With increasing usage of social media in all age, racial/ ethnic, and socioeconomic groups, availability of breast reconstructive options may also be disseminated directly to patients.

There are several limitations to this study. In order to retrospectively compare attitudes regarding breast reconstruction before and after law enactment in 2010, the survey design required the participants to recall patient education and referral patterns from the past. This recall bias likely resulted in an overestimation of law awareness and appropriate practice patterns, as dutiful oncologic surgeons may inaccurately remember educating and referring patients as they ought to have been. This study is also subject to selection bias, as only NYS breast surgeons who are also fellows of the American College of Surgeons were surveyed. These fellows are often academic in nature and may be given information disseminated mainly through surgical societies and other academic sources. Therefore, it is possible that these information sources as well as the likelihood of discussion of reconstructive options with patients may be overestimated. Given our interest in a particular NYS law, only breast surgeons who practiced in NYS were relevant to the study, but this restriction, as well as the $11 \%$ survey response rate limited the sample size. Finally, while corroboration of previous outcomes research with this provider-based study strengthens the argument for the law's impact, without a prospective, controlled study, causality cannot be demonstrated. As knowingly not disclosing the presence of a law that increases access to care is unethical, a randomized controlled study on the effect of the Provider Discussion Law is difficult. A survey of patients in the future would supplement the current study and previous outcomes research. Analysis of a policy from multiple angles is key to fully understanding the impact. Continued outcomes-based and provider-based research will be integral to future health policy studies which will, in turn, inform and shape future policies for continual improvement of patient care.

\section{Acknowledgments}

Funding: None.

\section{Footnote}

Data Sharing Statement: Available at http://dx.doi. org/10.21037/jhmhp-20-13

Conflicts of Interest: All authors have completed the ICMJE uniform disclosure form (available at http://dx.doi. org/10.21037/jhmhp-20-13). The authors have no conflicts of interest to declare.

Ethical Statement: The authors are accountable for all aspects of the work in ensuring that questions related to the accuracy or integrity of any part of the work are appropriately investigated and resolved. The Columbia University Medical Center Institutional Review Board determined that the survey met exemption criteria.

Open Access Statement: This is an Open Access article distributed in accordance with the Creative Commons Attribution-NonCommercial-NoDerivs 4.0 International License (CC BY-NC-ND 4.0), which permits the noncommercial replication and distribution of the article with the strict proviso that no changes or edits are made and the original work is properly cited (including links to both the formal publication through the relevant DOI and the license). See: https://creativecommons.org/licenses/by-nc-nd/4.0/.

\section{References}

1. Siegel RL, Miller KD, Jemal A. Cancer Statistics, 2018. CA Cancer J Clin 2018;68:7-30.

2. Reaby L. Reasons why women who have mastectomy decide to have or not to have breast reconstruction. Plast Reconstr Surg 1998;101:1810-8.

3. Wellisch DK, Schain WS, Noone RB, et al. Psychosocial correlates of immediate versus delayed reconstruction of the breast. Plast Reconstr Surg 1985;76:713-8.

4. Eltahir Y, Werners LL, Dreise MM, et al. Qualityof-life outcomes between mastectomy alone and breast reconstruction: comparison of patient-reported BREAST-Q and other health-related quality-of-life 
measures. Plast Reconstr Surg 2013;132:201e-209e.

5. Atisha D, Alderman AK, Lowery JC, et al. Prospective analysis of long-term psychosocial outcomes in breast reconstruction: two-year postoperative results from the Michigan Breast Reconstruction Outcomes Study. Ann Surg 2008;247:1019-28.

6. Howard-McNatt MM. Patients opting for breast reconstruction following mastectomy: an analysis of uptake rates and benefit. Breast Cancer (Dove Med Press) 2013;5:9-15.

7. Alderman AK, Hawley ST, Janz NK, et al. Racial and ethnic disparities in the use of postmastectomy breast reconstruction: results from a population-based study. J Clin Oncol 2009;27:5325-30.

8. Greenberg CC, Schneider EC, Lipsitz SR, et al. Do variations in provider discussions explain socioeconomic disparities in postmastectomy breast reconstruction? J Am Coll Surg 2008;206:605-15.

9. Preminger BA, Trencheva K, Chang CS, et al. Improving access to care: Breast surgeons, the gatekeepers to breast reconstruction. J Am Coll Surg 2012;214:270-6.

10. Fu R, Kurlansky PA, Means J, et al. Breast Cancer Provider Discussion Law Helps Reverse Racial and Economic Disparity in Breast Reconstruction Rates in New York State: An Analysis of 42,137 Patients from the New York State Database. J Am Coll Surg 2017;225:S160-1.

11. Dossett LA, Hudson JN, Morris AM, et al. The Primary Care Provider (PCP)-Cancer Specialist Relationship: A Systematic Review and Mixed-Methods. CA Cancer J Clin 2017;67:156-69.

12. Mead EL, Doorenbos AZ, Javid SH, et al. Shared Decision-Making for Cancer Care Among Racial and Ethnic Minorities: A Systematic Review. Am J Public Health 2013;103:15-29.

doi: 10.21037/jhmhp-20-13

Cite this article as: Toyoda Y, Lin AJ, Rohde CH. Implications of public policy on breast reconstruction: a survey of New York State breast surgeons on the breast cancer provider discussion law. J Hosp Manag Health Policy 2020;4:22.
13. Phelan JC, Link BG, Tehranifar P. Social conditions as fundamental causes of health inequalities: theory, evidence, and policy implications. J Health Soc Behav 2010;51 Suppl:S28-40.

14. May FP, Almario C V, Ponce N, et al. Racial Minorities Are More Likely Than Whites to Report Lack of Provider Recommendation for Colon Cancer Screening. Am J Gastroenterol 2015;110:1388-94.

15. Maly RC, Leake B, Silliman RA. Breast cancer treatment in older women: impact of the patient-physician interaction. J Am Geriatr Soc 2004;52:1138-45.

16. Ward E, Jemal A, Cokkinides V, et al. Cancer disparities by race / ethnicity and socioeconomic status. CA Cancer J Clin 2004;54:78-93.

17. Nelson HD, Tyne K, Naik A, et al. Screening for Breast Cancer: An Update for the U.S. Preventive Services Task Force. Ann Intern Med 2009;151:727-37.

18. Butler PD, Nelson JA, Fischer JP, et al. Racial and age disparities persist in immediate breast reconstruction: an updated analysis of 48,564 patients from the 2005 to 2011 American College of Surgeons National Surgery Quality Improvement Program data sets. Am J Surg 2016;212:96-101.

19. Fu R, Chang MM, Chen M, et al. A Qualitative Study of Breast Reconstruction Decision-Making among Asian Immigrant Women Living in the United States. Plast Reconstr Surg 2017;139:360e-368e.

20. Wakefield MA, Loken B, Hornik RC. Use of mass media campaigns to change health behaviour. Lancet 2010;376:1261-71.

21. Bottorff JL, Struik LL, Bissell LJ, et al. A social media approach to inform youth about breast cancer and smoking: an exploratory descriptive study. Collegian 2014;21:159-68. 